\title{
Leptin Receptor Deficiency
}

National Cancer Institute

\section{Source}

National Cancer Institute. Leptin Receptor Deficiency. NCI Thesaurus. Code C120386.

Deficiency or dysfunction of the leptin receptor associated with loss-of-function

mutation(s) in the LEPR gene. 